\title{
The different roles of Griffonia simplicifolia in the treatment of depression: a narrative review
}

\begin{abstract}
Introduction: Several studies have demonstrated the importance of some plants for the treatment of depression because they are sources of 5-hydroxytryptophan (5-HTP), among them, Griffonia simplicifolia stands out, especially when dosed and formulated as an herbal remedy.

Objective: The purpose of this article is to conduct a narrative review on the treatment of depression through the phytotherapic Griffonia simplicifolia.

Method: A bibliographic review and a search of the electronic index databases MEDLINE/ PubMed, Web of Science, CAPES journal portal, BIREME and Google Scholar were carried out.

Results: Phytotherapy is only equivalent to allopathy only in the use of the law of the like. However, its substances come only from vegetable origin. Thus, unlike allopathic drugs, it cannot be called a drug, but an active principle. Thus, both allopathy and phytotherapy agree to increase the availability of 5-HT in the treatment of depression. In this sense, among these medicinal plants tested in the laboratory, this study chose Griffonia simplicifolia that presents pharmacodynamic conditions for the treatment of depression because it is a source of 5-hydroxytryptophan (5-HTP). Research has shown that Griffonia simplicifolia extracts increase the level of serotonin in the brain. Each seed is estimated to contain about 6 to $14 \%$ of 5-HTP. In some countries, after an industrial extraction, the researchers combine the contents of several seeds to provide $95-98 \%$ of 5 -HTP in each capsule.
\end{abstract}

Conclusion: The studies presented in this narrative review demonstrate that 5 -HTP extracted from Griffonia simplicifolia can be effective in the treatment of fibromyalgia, chronic headaches, insomnia, in the anxiety control and, above all, in depression.
Volume 14 Issue 3 - 202 I

\author{
Renata de Melo Guerra Ribas,' Diélita \\ Carla Lopes de Oliveira,' Paulo César \\ da Silva,' Hugo André de Lima Martins,' \\ Joyce Gomes de Moraes,' Mayara Paula da \\ Silva, 'Valdenilson Ribeiro Ribas,' Clenes \\ de Oliveira Mendes Calafange, ${ }^{2}$ Ana Elisa \\ Toscano Meneses da Silva Castro, ${ }^{2}$ Raul \\ Manhães de Castro ${ }^{2}$ \\ 'Brain Institute of Pernambuco (ICerPE), Brazil \\ ${ }^{2}$ Postgraduate Program in Neuropsychiatry and Behavioral \\ Sciences (Posneuro), Brazil
}

Correspondence: Valdenilson Ribeiro Ribas, Senador Sérgio Guerra, 220,Apt. 132, Piedade - Jaboatão dos Guararapes, Tel 54.400-003,Email ribas.professor@gmail.com

Received: May 22, 2021 | Published: June 09, 2021

Keywords: phytotherapy, griffonia simplicifolia, depression

\section{Introduction}

\section{Medicinal plants - historical aspect}

The oldest recorded entry on the use of medicinal plants for the purpose of making a pharmacological compound for the treatment of diseases was found on a chalkstone, from approximately 3000 BC, from the ancient Sumerian civilization in Nagpur, a city in India, in the state of Maharashtra. ${ }^{1,2}$ In this registry, 12 formulations were found for the organization and preparation of drugs consisting of more than 250 different herbs.

There are reports in the literature that put the Egyptian civilization in this dispute for the pioneering of the discoveries of medicinal plants, dating from 6000years ago, approximately 4,000 BC, however, it includes, in addition to plants, products of animal origin. ${ }^{3}$

Then, this dispute approaches, the Chinese book on roots and grasses, written by Emperor Shen Nung around 2500 BC, which discusses about 365 medicinal substances, derived from the dry parts of different plants and, at the same time, the encyclopaedia of the days Chinese medical material published in 1977 registered almost 6000 medicinal substances, of which 4800 are of plant origin. ${ }^{1}$

The use of medicinal plants was also widespread among the peoples of India, around 2000years ago. ${ }^{4}$ The Indian sacred books, Vedas, composed in a language called Vedic Sanskrit, mention the treatment with plants, which are abundant in that country. Many spice plants used today are from India, such as: nutmeg, pepper, cloves, among others. ${ }^{1}$

The peoples of Mexico and Central America, the Aztecs, have been exploring the effectiveness of medicinal herbs for at least 1000years, even referring to treatments for simple diseases, such as acne, even the most complex, such as epilepsy. ${ }^{3}$

In ancient history, the most relevant record on plant drugs was prepared by the Greco-Roman author, Pedânio Dioscórides, considered the founder of pharmacognosy, who, as a military doctor and responsible for pharmacology in Nero's army, studied medicinal plants. Around $77 \mathrm{AD}$, he wrote a work, ${ }^{5}$ divided into 5 books, where, of the total of 944 drugs described, 35 drugs were of animal origin, 90 of mineral origin, of which only about 130 already appeared in the Corpus hippocraticum and 657 were of vegetable origin. ${ }^{1}$

The great strength and the first leap, which made it possible to study the effects of medicinal plants, was given by a Swedish botanist, zoologist and physician, Carolus Linnaeus, creator of binomial nomenclature and scientific classification, considered the founder of modern taxonomy, who documented and classified in a standardized manner thousands of botanical species about medicinal plants in the 18th century. Species Plantarum was first published in 1753 in two volumes. ${ }^{6}$

Anyway, there are several studies that address the effects of medicinal plants on diseases that affect the liver, kidneys, stomach, 
intestines, among others. However, due to the complexity surrounding the central nervous system, the most surprising studies are the findings that involve the effect of the treatment of various mental illnesses, including depression through some plants, which are sources of 5-hydroxytryptophan (5-HTP). ${ }^{7}$

\section{Serotonergic neurotransmission and depression}

The synthesis of the neurotransmitter 5-hydroxytryptamine or cerebral 5-HT serotonin occurs in the central nervous system, from the essential amino acid L-tryptophan ${ }^{8}$ and depends on the nutrition and balance of the intestinal microbiota. ${ }^{9}$

However, when it comes to nutrition biochemistry, it seems relevant not to think in a reductionist way, because it is not an isolated effect, but a complex process that involves the interaction of several nutrients, such as: vitamin B6, in the form of pyridoxal-5-phosphate, because it is water-soluble, acts on the biosynthesis of 5-HT, transporting atoms and electrons in the decarboxylation process, folic acid (vitamin B9) and cobalamin (vitamin B12) ${ }^{10}$ in the transmethylation process for control of the number of neurotransmitters, $1^{0}$ and the main raw material for this serotonergic genesis, which is the essential amino acid L-tryptophan, together with vitamin $\mathrm{D}$, regulating the synthesis of serotonin and degradation. ${ }^{11}$

In this sense, foods containing L-tryptophan are of fundamental importance in serotonergic neurotransmission. However, the participation of L-tryptophan still goes beyond neurotransmitter genesis, because part of it is converted in the liver to niacin (vitamin B3) ${ }^{12}$ with the help of enzymes that contain vitamin B6 and iron and this niacin associated with pyruvate, omega 3, omega 6 and oxygen are essential in the mitochondria to enable the Krebs cycle, oxidative phosphorylation, formation of ATP, firing of neurons ${ }^{13}$ and, consequently, it allows the production of Delta brain waves $(2-4 \mathrm{~Hz})$, Theta (4-7Hz), Alpha (8-12Hz), Beta-Low (12-15Hz), BETA (15$23 \mathrm{~Hz})$, Beta-High $(23-38 \mathrm{~Hz})$ and Gamma $(38-42 \mathrm{~Hz}){ }^{14}$

In this context, one cannot fail to mention the minerals that are essential for the realization of the entire biochemical process, such as: phosphorus, which is important for $\mathrm{pH}$ regulation and for the action of vitamin D3 and calcium and, above all, , which is essential for the assimilation of niacin (also called nicotinamide or Vitamin B3) $;{ }^{15}$ sulphur, which makes up necessary amino acids for the synthesis of essential metabolites and also makes up thiamine and biotin; copper, which is a constituent of enzymes and substances in the blood with an important role in the oxidation of iron before it is transported in plasma; manganese, which is a constituent of essential enzyme systems, abundant in mitochondria, responsible for cellular respiration of liver cells, bone formation, cholesterol synthesis, thiamine activation, glucose metabolism, synthesis and the release of hormones from thyroid and prevention of allergic processes. ${ }^{16}$

Specifically, in neurotransmission, when L-tryptophan is transported into the serotonergic neuron, it undergoes the action of the enzyme tryptophan hydroxylase in the cytoplasm, transforming into 5-hydroxytryptophane. ${ }^{17}$ Tryptophan (5-HTP) is decarboxylated through unspecific action of the amino acid-decarboxylase enzyme and, after the enzymatic action is converted to serotonin $(5-\mathrm{HT}) .{ }^{18}$

The process of degradation and inactivation of 5-HT is carried out by a reuptake mechanism, where 5 -HT passes through a membrane transporter and after two reactions results in its main metabolite, 5-hydroxyindolacetic acid (5-HIAA). ${ }^{19}$

Currently, there are about seven types of serotonergic receptors identified, they are: 5-HT1, 5-HT2, 5-HT3, 5-HT4, 5-HT5, 5-HT6 and 5-HT7. ${ }^{20}$ Several receptor subtypes have also been described and classified, such as 5-HT1A and 5-HT1B, among others. ${ }^{18}$

A wide variety of central nervous system functions have the role of serotonin. It is also important to highlight the role of this neurotransmission system in controlling aggressiveness, ${ }^{21}$ anxiety ${ }^{22}$ and depression..$^{23}$ In depression, during the synapse, the 5-HT released from the synaptic vesicle, detaching itself from the presynaptic neuron, when in the cleft, it should go to a postsynaptic receptor, but it does not, and returns to the same pre neuron -synaptic by transmembrane protein, only this time, without the protection of the synaptic vesicle, it is degraded by the enzyme monoaminaoxidase (MAO), transforming into 5-hydroxyindole acetic acid (5-HIAA). ${ }^{24}$

\section{Specifications of drug treatment approaches}

Drug treatment can take place in three different approaches: allopathy, homeopathy and phytotherapy or even by an informal, uncontrolled and alternative method using medicinal plants without control of standardized doses, called home remedies.

\section{Allopathy}

The law of similars is used in allopathy, ${ }^{25}$ In allopathy, the law of similars is used, that is, medicines are used that, in the body, cause effects contrary to the disease, seeking to eliminate the discomfort generated by the symptoms. ${ }^{26}$ The production of the medication comes from animal or vegetable origin and this drug can be called a drug or medication, which can be a synthetic drug manufactured in the laboratory. ${ }^{27}$

Allopathic drugs make it possible to increase serotonergic availability in synaptic clefts in the case of depression. ${ }^{27}$ They can act directly on the receptors, as agonists or antagonists, but they can also play the role of reuptake inhibitors, blocking transmembrane proteins. ${ }^{28}$

Allopathy is usually accepted by government oversight institutions in most countries throughout the world, because they meet the requirements of scientific evidence established by the natural sciences, with high percentages of confidence interval, between $95 \%$ and $99 \%$, guaranteeing the minimum probability of error expressed in the level of statistical significance, referenced, from the normal Gaussian curve. $^{28}$

\section{Homeopathy}

Homeopathy works with the law of opposites ${ }^{26}$ using substances that slightly aggravate symptoms in order to make the body stronger to fight it. The substance is derived from the three kingdoms: animal, vegetable or mineral in the homeopathic approach. ${ }^{29}$

In the preparation of the substance, the first centesimal is used, where a substance is diluted in 99 drops of water. ${ }^{29}$ If there is no response from the organism, the second centesimal is prepared, diluting that substance already diluted in another 99 drops of water and so on, following the healing energy vis medicatrix naturae, letting nature do its own work. ${ }^{30}$

However, the rule of not diluting 12 times is maintaine. ${ }^{26}$ The professionals of this approach use the Avogadro number (as a reference for the preparation of the substance), indicating the number of atoms of Carbon-12, which together represent $12 \mathrm{~g}$ of the substance - 1 mol of C-12. The name of the constant is a tribute to the researcher Amedeo Avogadro. ${ }^{31}$ Thus, it is not diluted 12 times, because in this principle, if it is diluted 12 times, matter is lost. ${ }^{32}$ 


\section{Phytotherapy}

Phytotherapy is equivalent to allopathy only in the use of the law of similars. However, its substances come only from plant origin. ${ }^{33}$ Thus, unlike allopathic medicines, it cannot be called a drug, but rather, an active ingredient. ${ }^{34}$ Even with these different singularities, both allopathy and phytotherapy agree to increase the availability of 5-HT in the body and, mainly, in the synaptic cleft, in the treatment of depression. ${ }^{35}$

In this sense, among these medicinal plants tested in the laboratory, this study chose Griffonia simplicifolia, because, in addition to presenting pharmacodynamic conditions for the treatment of depression as a source of 5-hydroxytryptophan (5-HTP), ${ }^{36}$ the Griffonia simplicifolia has the advantage of helping a larger number of people, since its seed can contain up to $14 \%$ of 5-HTP, considering that a capsule can contain up to $98 \%$ of 5 -HTP. ${ }^{37}$

\section{Method}

It is a study with a qualitative, exploratory and descriptive approach; source and bibliographic collection procedure. A narrative review was carried out through a search in the electronic indexing bases MEDLINE / PubMed, Web of Science, CAPES journals portal, BIREME and Google Scholar.

\section{Results}

\section{Griffonia simplicifolia}

Griffonia is a plant from tropical Africa ${ }^{38}$ and belongs to the Cercideae or Cercidoideae tribe, which is a subfamily of the pea family, Fabaceae. ${ }^{39}$ There are 4 species of Griffonia. They are: 1) Griffonia physocarpa, 2) Griffonia tessmannii and 3) Griffonia speciosa, which are more common species in Nigeria, east of the Democratic Republic of Congo and south for Angola, although they are less common than 4) Griffonia simplicifolia. ${ }^{40}$ Griffonias physocarpa, tessmannii and speciosa have similar medicinal uses, such as treatment of gonorrhoea and stomach discomfort through decoction. Griffonia physocarpa, speciosa and simplicifolia seeds contain high concentrations of 5-HTP. ${ }^{40}$

Griffonia simplicifolia of the Fabaceae family of the dicotyledonous class is a common shrub in western and central Africa, especially in the Republic of Ghana, the Republic of Côte d'Ivoire and the Togolese Republic. ${ }^{41,42}$

This plant can take the form of a climbing plant, especially when it grows near tall trees. Griffonia can grow up to 3 meters. ${ }^{43}$ The flowers produce black fruits with seeds that can be used as a source of 5-hydroxytryptophan (5-HTP). ${ }^{44}$

Several researches have been showing that Griffonia simplicifolia plant extracts increase the level of serotonin in the brain. Each seed is estimated to contain about 6 to $14 \% 5-\mathrm{HTP}^{37}$ in addition, the leaves of plants contain serotonin in concentrations 0.1 to $0.2 \%{ }^{45}$

In some countries (United Kingdom, USA, Canada and Germany), after an industrial extraction, researchers combine the contents of several seeds to make available in each capsule $95-98 \%$ of 5-HTP (TEIXEIRA et al., 2016), mixed with vitamins or with green tea or even yerba mate. ${ }^{45}$

In this form, Griffonia extracts are used as supplements to help treat depression, reduce appetite and induce sleep. These products commonly contain $50-100 \mathrm{mg}$ of 5 -HTP. ${ }^{46} 5$-HTP, when ingested, interacts with vitamin B6 and is converted to serotonin in the CNS. ${ }^{47}$ During the absorption of 5-HTP there is no need for a special transport molecule. Absorption is also not influenced by amino acids, which allows 5-HTP to be administered with meals, without losing its effectiveness. ${ }^{47}$ The great advantage of 5-HTP extracted from Griffonia simplicifolia is that it easily crosses the blood-brain barrier - it does not require the presence of a transport molecule and it does not compete with other amino acids to enter the brain. ${ }^{48}$ Therefore, it is well absorbed after oral administration $(70 \%$ of the dose is introduced into the bloodstream) ${ }^{37}$

Another scientific evidence of great relevance was observed in a study in the field of basic neuroscience with Griffonia simplicifolia seed extract on the behavior of anxiety in rats in the open field test. ${ }^{49}$ In this test, animals tend to hide in the dark space, as a form of protection from predators. Normally, animals do not spend much time in the light area. When exposed to the open field of light, they tend to manifest psychophysiological behaviors of fear and anxiety, such as: urine, fecal cakes and tremors. In the dark light test, administration of the extract at doses of 10 and $25 \mathrm{mg} / \mathrm{kg}$ was able to significantly increase the time spent in the light compartment. ${ }^{49}$

More very expressive evidence of 5-HTP in Griffonia simplicifolia was observed in one study ${ }^{46}$ where Griffonia 5-HTP extract was administered via spray in the oral cavity, and the adequacy of absorption was confirmed by increasing the urinary 5-HIAA by $24 \mathrm{~h}$, and that the supplementation of the diet of women with excess of weight with 5-hydroxytryptophan increased the feeling of satiety associated with a decrease in body mass index (BMI). ${ }^{46}$

It has also been shown that therapeutic administration of 5-HTP can be effective in depression, ${ }^{50}$ fibromyalgia, ${ }^{51}$ chronic headaches and insomnia. ${ }^{1}$ It also seems that Griffonia's role goes beyond the 5-HTP offer, because, in Giurleo's study, carried out in 2017,52 found in Griffonia Simplicifolia, a great source of iron, zinc, copper and magnesium. ${ }^{51}$ This study seems to allow another relevant reflection regarding the role of Griffonia simplicifolia in the treatment of depression, since iron and micronutrients (zinc and copper) allow an increase in the availability of oxygen at the mitochondrial level, ${ }^{53}$ enabling the Krebs cycle, oxidative phosphorylation, ATP generation, exothermic energy and quality neuron firing. ${ }^{13}$

As for magnesium also found in Griffonia simplicifolia, it seems relevant to emphasize its role as an activator of several enzymes, participating in most organic processes, helping to control sodium and potassium, ${ }^{54}$ and also acting in the neuromuscular process, ${ }^{55}$ in the functioning of the immune ${ }^{56}$ and cardiovascular system. ${ }^{57}$

In this sense, cardiovascular performance seems to be enriched with magnesium ${ }^{55}$ and, indirectly, it also contributes to the protection of depressive processes, ${ }^{50}$ since it works, pumping blood in the transport of oxygen to the mitochondria. ${ }^{13}$

Another recent finding ${ }^{58}$ of phytochemical research seems to corroborate this cardiovascular role in the process of optimizing brain functioning, because, in Griffonia simplicifolia, it also revealed the presence of secondary metabolites ${ }^{50}$ such as alkaloids, triterpenoids, flavonoids, steroids, saponins, glycosides, phenols, tannins and coumarins, demonstrating that this cardiovascular functioning can be further enhanced by the therapeutic properties in the treatment of opportunistic bacterial infections and diseases associated with oxidative stress $^{58}$ increasing, thus, the availability of functional oxygen to the cortical mitochondria.

Even though it is known that Griffonia simplicifolia is a herbal medicine, there is a need to be careful with the possibility of interaction with other substances. ${ }^{50} \mathrm{~A}$ recent study ${ }^{59}$ with a 42 -yearold male patient who developed hypomania after a week of using Nutraceutical S-Adenosyl-L-Methionine (SAMe) associated with 
5-hydroxytryptophan (5-HTP) for the treatment of depression, it demonstrated that this combination can induce hypomanic episodes. ${ }^{59.60} \mathrm{~S}$-Adenosyl-L-Methionine is a substance that has been used as a supplement to stimulate mood and help decrease joint stiffness and liver function. ${ }^{61}$

Another very significant aspect of Griffonia simplicifolia in the treatment of depression may be the improvement in sleep quality. 5-HTP undergoes a decarboxylation process through the enzyme 5-HTP decarboxylase, giving rise to serotonin. ${ }^{62}$ In one of its metabolic routes, serotonin is acetylated by the enzyme AA-NAT, giving rise to $\mathrm{N}$-Acetylserotonin (NAS) which, in turn, is methylated by HIOMT to form melatonin. ${ }^{63}$

The last contribution of this narrative review on the important roles of Griffonia simplicifolia in the treatment of depression would be its indication for controlling anxiety indirectly. ${ }^{64,65}$ According to Neurologist Sigmund Freud, while infectious diseases are caused by pathogens, mental illnesses have their aetiologies in uncontrolled anxiety. Although Freud brought this information in the context of ego defences, as ways of thinking that minimize symptoms of anxiety (mechanisms of psychic defences), it cannot be denied, that several physical phenomena also participate in the control of anxiety, among them: breathing, the adrenal gland, respiratory microcirculation and neurotransmitters. ${ }^{50}$

\section{Conclusion}

This narrative review found several studies, demonstrating that Griffonia simplicifolia plant extracts increase the level of serotonin in the brain. The studies presented in this narrative review demonstrate that each Griffonia simplicifolia seed can contain up to $14 \%$-HTP. It was also observed in this review article that countries in the United Kingdom, United States of America, Canada and Germany gather the contents of several seeds to make 95-98\% 5-HTP available in each capsule.

The great advantage of 5-HTP extracted from Griffonia simplicifolia is that it easily crosses the blood-brain barrier and $70 \%$ of the dose is absorbed into the bloodstream after oral administration. It was also shown that the therapeutic use of 5-HTP can be efficient in the treatment of fibromyalgia, chronic headaches, insomnia, in controlling anxiety and, above all, in depression.

\section{Acknowledgments}

None.

\section{Conflicts of interest}

Author declares there are no conflicts of interest.

\section{Funding}

None.

\section{References}

1. Petrovska BB. Historical review of medicinal plants' usage. Pharmacogn Rev. 2012;6(11):1-5.

2. Solomou AD, Martinos K, Danalatos N, et al. Medicinal and Aromatic Plants Diversity in Greece and Their Future Prospects: A Review. Agricultural Science. 2016;4:9-20.

3. Silva AAD. Knowledge and beliefs about the use of medicinal plants in the treatment of headaches. 2015.

4. CARVAlHO, A. C. B. Medicinal and phytotherapic plants: sanitary regulation and proposal of a monograph model for plant species officialized in Brazil. Medicinal Plants Herbal Medicine Herbal Medicines. 2011.
5. Grosso AF. Cannabis: de planta condenada pelo preconceito a uma das grandes opções terapêuticas do século. Journal of Human Growth and Development. 2020;30(1):94-97.

6. Kataoka EY. Plant systematics: history, concepts and current status. Winter botany: Marine Algae Laboratory; 2017. p. 130.

7. Branco DMD, Costa T. Relationship between the action of 5hydroxytriptophan and the effect on saciety and mood in overweight and obesity women after oral administration of gryffhonia simplicifolia extract capsules. Revista InterCiência-IMES Catanduva. 2019;1(2):53-53.

8. Martins ACC, Silva TM, Gloria MBA. Simultaneous determination of serotonin precursors - tryptophan and 5-hidroxytryptophan - in coffee. Química Nova. 2010;33(2):316-320.

9. Brito JS, Borges NA, Dolenga CJR, et al. Is there a relationship between tryptophan dietary intake and plasma levels of indoxyl sulfate in chronic kidney disease patients on hemodialysis? / Is there a relationship between dietary intake of tryptophan and plasma levels of indoxyl sulfate in chronic renal patients undergoing hemodialysis? Brazilian Journal of Nephrology. 2016;38(4):396-402.

10. Almeida OP, Ford AH, Flicker L. Systematic review and meta-analysis of randomized placebo-controlled trials of folate and vitamin B12 for depression. Int Psychogeriatr. 2015;27(5):727-377.

11. Patrick RP, Ames BN. Vitamin D hormone regulates serotonin synthesis. Part 1: relevance for autism. FASEB J. 2014;28(6):2398-2413.

12. DE Maria CAB, Moreira RFA. A intrigante bioquímica da niacina-uma revisão crítica. Quim Nova. 2011;34(10):1739-1752.

13. Ribas VR, Ribas RMG, Oliveveira DLC, et al. The Functioning of the Brain Trained by Neurofeedback with Behavioral Techniques from a Learning Curve Perspective. J Psychol Psychother Res. 2016b;3(2):1219.

14. Ribas VR, Guerra Ribas RM, Martins HAL. The learning curve in neurofeedback of peter van deusen: A review article. Dement Neuropsychol. 2016;10(2):98-103.

15. Yasmeen G, Dawani ML, Mahboob T. Hypophosphatemic effect of niacin extended release in ischemic kidney disease. EXCLI J. 2015;14:10951103.

16. Salway JG. Metabolism at a Glance. USA: John Wiley \& Sons; 2016.

17. Vieira B RM. Effect of dietary supplementation with tryptophan on aggressive behavior in Nile tilapia juveniles. 2013.

18. Vedovato K, Trevizan AR, Zucoloto CN. The Intestine-Brain Axis and the Role of Serotonin. UNIPAR Health Science Archives. 2014;18(1).

19. Melo DD. Neonatal exposure to serotonin reuptake inhibitor: analysis of components of the serotoninergic system. Brazil: Federal University of Pernambuco UFPE (Federal University of Pernambuco); 2014.

20. Carvalho MS. Participation of spinal serotoninergic and noradrenergic receptors in the antinociceptive effect of interferential current in an animal model of joint inflammation. 2019.

21. Narvaes RF. Aggressive behavior and three central neurotransmitters: dopamine, gaba and serotonin: a systematic review of the last 10 years. Revista modelo: Psychology and Neuroscience. 2013.

22. Brito I. Anxiety and depression in adolescence. Revista Portuguesa de Clínica Geral. 2011;27(2):208-214.

23. Bonemann GS, Lopes CM, Freitas H. The Relationship of Serotonin and Depression. Anais Do XI Evinci. 2016;2(1):27-27.

24. Monteiro LDB. Depression: mechanisms involved, pharmacotherapy and the role of SUS. 2016.

25. Battello C. Homeopathy X Allopathy - An Approach on the Subject. Digitaliza. 2016. ISBN 8594860501.

26. Vanzela C, Bitencourt RM. Homeopathy: alternative therapy or placebo effect? Unoesc \& Ciência-ACBS. 2017;8(1):59-66. 
27. Muakad IB. Anfetaminas e drogas derivadas. Revista da Faculdade de Direito. Brazil: Universidade de São Paulo; 2013; p. 545-572.

28. https://estudogeral.sib.uc.pt/handle/10316/79697

29. Battello C. Homeopathy X Allopathy - An Approach on the Subject. Digitaliza. 2016. ISBN 8594860501.

30. Logan AC, Selhub EM. Vis Medicatrix naturae: does nature" minister to the mind"? BioPsychoSocial medicine. 2012;6(1)1-10.

31. Ciard M. Two hundred years after Avogadro's hypothesis: myth and historiography. Proceedings of the XIV National Convention of History and Foundations of Chemistry (Rimini, 21-23 September 2011). Accademia Nazionale delle Scienze detta dei XL. 2012;139-150.

32. Esperancinha LDD. Evaluation of the consumption of homeopathic products in the interior of Portugal: professional experience in community pharmacy and research. Brazil: Universidade da Beira Interior; 2012.

33. Ferreira V F, Pinto AC. A fitoterapia no mundo atual. Química Nova. 2010;33(9):1829-1829.

34. Argenta SC, Argenta LC, Giacomell SR, et al. Plantas medicinais: cultura popular versus ciência. Vivências. 2011;7(12):51-60.

35. Almeida AAC, Fonseca de Carvalho RB, Ladeira Coelho M, et al. Utilização de plantas medicinais para o tratamento da depressão: uma prospecção tecnológica. Revista GEINTEC-Gestão, Inovação $e$ Tecnologias. 2013;3(2):157-166.

36. Tyler VM, Russo EB. Handbook of psychotropic herbs: A scientific analysis of herbal remedies for psychiatric conditions. UK: Routledge; 2015

37. Vigliante I, Mannino G, Maffei ME. Chemical Characterization and DNA Fingerprinting of Griffonia simplicifolia Baill. Molecules. 2019;24(6):1032.

38. Fortunato RH. Revision del genero Bauhinia (Cercideae, Caesalpinioidea, Fabaceae) para la Argentina. Darwiniana. 1986;527-557.

39. Borges L. Towards a new classification system for legumes: Progress report from the 6th International Legume Conference. South African Journal of Botany. 2013;89.

40. Kumar PS, Praveen T, Jain NP, et al. A review on Griffonia simplicifolliaan ideal herbal anti-depressant. International Journal of Pharmacy and Life Sciences (IJPLS). 2010;1(3):174-181.

41. Beecham JE. Edible Compositions and Methods for Promoting Alpha Brain Waves: Google Patents. 2017.

42. Vivek P. Biodiversity and Community Ecology of Lianas in Tropical Dry Evergreen Forest of India. India; Pondicherry University; 2016.

43. Tuo K, Orega YB, Kouamé KBJ, et al. Characterization of weed flora in rubber trees plantations of Bongo (Côte d'Ivoire). Journal of Applied Biosciences. 2013;70(1):5544-5554.

44. IWU MM. Handbook of African medicinal plants. USA: CRC press; 2014.

45. Muszyńska B, Łojewski M, Rojowski J, et al. Natural products of relevance in the prevention and supportive treatment of depression. Psychiatr Pol. 2015;49(3):435-453.

46. Rondanelli M, Opizzi A, Faliva M, et al. Relationship between the absorption of 5-hydroxytryptophan from an integrated diet, by means of Griffonia simplicifolia extract, and the effect on satiety in overweight females after oral spray administration. Eat Weight Disord. 2012;17(1):e22-e28.

47. Peuhkuri K, Sihvola N, Korpela R. Diet promotes sleep duration and quality. Nutr Res. 2012;32(5):309-319.
48. Balogun MM, Jimoh MO, Ogundipe OT. Conservation of a Rare Medicinal Plant: A Case Study of Griffonia simplicifolia (Vahl ex DC) Baill. European Journal of Medicinal Plants. 2020;152-160.

49. Carnevale G, V Di Viesti, Zavatti M, et al. Anxiolytic-like effect of Griffonia simplicifolia Baill. seed extract in rats. Phytomedicine. 2011;18(10):848-851.

50. Maffei ME. Griffonia simplicifolia extract standardized in 5hydroxytryptophan and bioactive. L'Integratore Nutrizionale. 2019;22(2):1-3.

51. Nyarko R, Larbie C, Anning AK, et al. Phytochemical constituents, antioxidant activity and toxicity assessment of hydroethanolic leaf extract of Griffonia simplicifolia. International Journal of Phytopharmacology. 2019;10(1):6-18.

52. Giurleo D. A phytochemical exploration of Griffonia simplicifolia seeds and leaves. USA: The State University of New Jersey; 2017.

53. Ribas VR, Guerra Ribas RM, Tavares Viana M, et al. The Functional Neurometry of Nelson Alves Pereira Júnior: An Advanced Method of Mapping and Biofeedback Training of the Autonomic Nervous System Functions. Journal of Psychology and Psychotherapy Research. 2020;719

54. Ramirez AVG. The importance of magnesium in cardiovascular disease. International Journal of Nutrology. 2016;9(4);242-253.

55. Esposito M, Precenzano F, Sorrentino M, et al. A medical food formulation of griffonia simplicifolia/magnesium for childhood periodic syndrome therapy: an open-label study on motion sickness. J Med Food. 2015 18(8):916-920.

56. Macêdo ÉMC D. Amorim AMF, Cristine S. da Silva A, et al. Effects of copper, zinc and magnesium deficiency on the immune system of severely. Revista Paulista de Pediatria. 2010;28(3):329-336.

57. Cunha AR, Umbelino B, Correia ML, et al. Effects of Magnesium on Vascular Structure and Function. Revista do Hospital Universitário Pedro Ernesto. 2011;10(3):1-10.

58. Akoto OC, Acheampong A, Tagbor DP, et al. Determination of the antimicrobial and antioxidant activities of the leaf extracts of Griffonia Simplicifolia. Journal of Pharmacognosy and Phytochemistry. 2020;9(2):2020.

59. Olsufka W, Abraham MA. Treatment-emergent hypomania possibly associated with over-the-counter supplements. Ment Health Clin 2018;7(4):160-163.

60. Fetrow CW. Avila JR. Efficacy of the dietary supplement S-adenosyl-Lmethionine. Ann Pharmacother. 2001;35(11):1414-1425.

61. DE SOUSA BRAZ, de Paula AP, Diniz MFFM, et al. Use of nonpharmacological therapy, alternative and complementary medicine in fibromyalgia. Rev Bras Reumatol. 2011;51(3):269-282.

62. Carneiro BIC, Toscano AE, Lacerda DC, et al. L-tryptophan administration and increase in cerebral serotonin levels: Systematic review. Eur J Pharmacol. 2018;836:129-135.

63. Petrilli CL. Regulation of pineal gland activity by purinergic stimulation. Brazil: Universidade de São Paulo; 2012.

64. Da Silva CC, Silva LS, Carvalho RVO. The use of Griffonia Simplicifolia and Rhodiola Rosea 1. in obese women with eating compulsion/A UTILIZACAO DA GRIFFONIA SIMPLICIFOLIA E RHODIOLA ROSEA L. EM MULHERES OBESAS COM COMPULSAO ALIMENTAR. Revista Brasileira de Obesidade, Nutrição e Emagrecimento. 2018;12(70):265-275.

65. Teixeira G, Martins ES, Catarino L. Antidepressant Plant Species from the Portuguese-Speaking African Countries (PALOP). In: Editor. Herbal Medicine in Depression: Springer, 2016. p. 433-481. 